\title{
UNIVERSITY PROCESS OPTIMISATION THROUGH SMART CURRICULUM DESIGN AND BLOCKCHAIN-BASED STUDENT ACCREDITATION
}

\author{
Christos Kontzinos, Ourania Markaki, Panagiotis Kokkinakos, Vagelis Karakolis, \\ Stavros Skalidakis and John Psarras \\ Decision Support Systems Lab National Technical University of Athens, Greece
}

\begin{abstract}
The main goals of Higher Education Institutions (HEIs) are to develop the intellectual abilities of students as well as prepare them for entering the labor market. The connection between HEIs and the labor market is why the effectiveness and quality of the provided services of academic institutions tend to be evaluated in terms of the time it takes for their graduates to find employment. This paper presents work from the EU funded research project QualiChain that aims to transform and revolutionize the domain of public education as well as its interfaces with those of private education, the labor market, public and private organizations and society at large, drawing its added value proposition from the challenges currently faced in these domains. The ultimate goal of the project is the development of the QualiChain platform that will offer blockchain-enabled verification of education and other credentials as well as data analytics and decision support for process optimization. The platform will be validated via its implementation in four different pilot cases. The present paper focuses on the pilot of optimizing university operations through semantically enhanced data and advanced decision support algorithms that will be implemented in the National Technical University of Athens (NTUA).
\end{abstract}

\section{KEYWORDS}

Blockchain, Education, Labor Market, Verification, Curriculum Design, Student Accreditation

\section{INTRODUCTION}

When asked about the aim of Higher Education, most people would argue that its sole purpose is to meet the learning needs and aspirations of individuals through the development of their intellectual abilities and aptitudes throughout their lives. It is Higher Education after all that equips individuals to make the best use of their talents and the opportunities offered by society for self-fulfillment (South African Council on Higher Education 2013). However, in today's highly competitive environment, a major goal of higher education should be to address the development needs of society and provide the labor market with the ever-changing high-level competencies and expertise necessary for the growth and prosperity of a modern economy.

It is for that reason that the effectiveness of a country's tertiary education system is frequently assessed in terms of the respective unemployment rates, whereas the effectiveness and quality of the provided services of academic institutions themselves are accordingly and not unjustly evaluated in terms of the time it takes for their graduates to find employment. In spite of this informal correlation between education and the labor market though, the training curriculum of higher education institutions is often shaped with strictly academic criteria within an isolated environment and without thus taking into account the demands of the latter; not to mention that it is rarely modified, so as to incorporate recent developments particularly in technology-related fields, thereby ending up being obsolete and outdated. Another challenge that slows down the connection between academia and the labor market is the fact that education credentials are largely resisting the pull of technology often requiring paper documentation and time-consuming manual processes for their verification. This mainly has to do with the fact that higher education institutions (HEIs) keep student data in centralized databases and dedicated online systems that offer little or no interoperability. 
As such, to have more efficient curriculum design and trustworthy student accreditation, fundamental changes are required in the way that HEIs operate. It can be surmised from the above that the main problem is the lack of suitable IT infrastructures that can lead to more efficient procedures by providing structure to university data as well as some degree of automation. Apart from existing IT systems and infrastructures, there are several innovative technologies that HEIs could take advantage of to develop trustworthy and efficient solutions. Particularly, blockchain technology, as a decentralized, permanent, unalterable store of information can help with the archiving and trust issues around academic credentials, whereas computational intelligence found in the technological domains of algorithmic techniques, data analytics, and semantic analysis may facilitate decision making and optimize work practices concerning administrative processes, course updates, etc.

Under these circumstances, this paper presents QualiChain, an EU funded project targeting the creation, piloting and evaluation of a distributed platform for storing, sharing and verifying academic and employment qualifications. To inspire trust in the projected platform, QualiChain will take advantage of blockchain's innate properties for decentralization, immutability and data protection. One of the project's target goals is to show that by combining various innovative technologies (semantic enrichment, data analytics, decision support algorithms, etc.) to develop tools and services on top of a trustworthy blockchain infrastructure can not only cover student accreditation but has the potential for wider university process optimization. To test and validate the projected platform in the field of education, QualiChain involves a pilot targeting student accreditation, curriculum design, and process optimization within the School of Electrical \& Computer Engineering (ECE) of the National Technical University of Athens (NTUA). Along the above lines, the paper shall provide a comprehensive use case on how the aforementioned technologies may lead to university processes optimization and will discuss the added value and benefits generated for the stakeholders involved.

Section 1 introduces the scope of the present paper by presenting the current situation in Higher Education and explaining how blockchain and other innovative technologies can lead to more effective and secure solutions. Section 2 presents in greater detail the challenges faced by universities today as well as blockchain solutions that have been applied to address them. Section 3 introduces the QualiChain concept and describes the pilot use case to be applied in the ECE School of the NTUA. Finally, Section 4 concludes the paper and describes the future actions that will be taken to realize the project goals.

\section{BACKGROUND}

\subsection{Current Challenges}

Institutions of higher education are operating in an increasingly complex and competitive environment. They are under increasing pressure to respond to constant economic, political and social change such as growing student demands in certain disciplines, embedding workplace attributes to graduates and ensuring that the quality of learning programs is both nationally and globally relevant (Daniel 2015), especially in an era of rapid technological change. Furthermore, the increasing amounts of fraud and corruption around higher education degrees and credentials (Chapman and Lindner 2014; Mohamedbhai 2016) is shaking the trust in the education system. Consequently, various stakeholders (academia, private/public sector, public administration, etc.) are expecting HEIs to address the growing regulatory demands for transparency and accountability (Hazelkorn 2007).

In light of the aforementioned challenges, the slow digitization of the education sector is a major concern (Association of Universities in the Netherlands (VSNU) 2017). Even though existing IT infrastructures in universities support most of the logistic processes, such as timetabling courses and student administration, their databases are often hosted in centralized data centers inside the university, with restricted access to its IT professionals (Turkanovic et al. 2018). However, such data are reflective of how students learn (Koedinger, K. et al. 2008) and how HEIs operate and if analyzed, could generate knowledge that would help institutions respond effectively to changes happening within and outside them (Daniel 2015). Another shortcoming of current IT systems is that they seldom provide any usability and interoperability in education credential sharing. Such documents mainly exist in paper form and require extremely time-consuming processes for their verification. Hence, students can experience difficulties transferring to another HEI or 
applying for a job due to the inaccessibility and lack of standardization of their records. While there are different degrees of digitisation among HEIs and there are certainly universities with more modernized processes compared to others, current challenges arise from the lack of common ground between such institutions as well as their connections with the labor market. While, the remarks made throughout this document may seem more generalized than need be, the aim is to indicate the need for standardization of data and common processes in the sector.

\subsection{BlockChain Potential for University Processes Optimization}

To tackle the challenges described in the previous section fundamental changes are required in the way that HEIs operate. At the same time, innovative technologies uncover new possibilities for higher education and learning in general. Blockchain is one such technology that has been employed by several higher education institutions to design different solutions and approaches related to higher education. Specifically, the University of Nicosia, having a leading role in academia-oriented blockchain initiatives, was the first higher education institution to issue academic certificates whose authenticity can be verified through the Bitcoin blockchain (2017). Additionally, Sony Global Education has developed a blockchain for storing academic records, leveraging blockchain's secure properties to realize encrypted transmissions (2016). Sharples and Domingue (2016), drawing on their previous research into reputational management for educational systems, proposed a permanent distributed record of intellectual effort and associated reputational reward, based on the blockchain, that instantiates and democratizes educational reputation beyond the academic community. In more recent approaches, Rooksby and Kristiyan (2017) have implemented a blockchain system based on Ethereum for use by a university to store student grades and to provide a cryptocurrency. Moreover, Skiba (2017) took advantage of blockchain as a distributed ledger to allow students to own their credentials and in combination with new forms of digital credentials (badges, certification documents) make the job of checking and validating transcripts for courses attended in different universities/colleges easier by providing a more secure and trustworthy system that eliminates the middleman from the task of verifying transactions. Finally, Turkanovic (2018) proposed a global higher education credit platform, named EduCTX that is based on the concept of the European Credit Transfer and Accumulation System (ECTS), while Gräther (2018) developed the Blockchain for Education platform as a practical solution for issuing, validating and sharing of certificates.

\section{QUALICHAIN APPROACH}

QualiChain is a project that aspires to investigate and provide evidence on the transformative impact of disruptive technologies, such as blockchain, semantics, data analytics and gamification in the domain of public education, as well as the interfaces of the latter with the fields of private education, the labor market, and public sector administrative procedures. The concept and focus of the project lie more specifically in the design, implementation, piloting and thorough evaluation in terms of benefits, risks and other potential implications of the QualiChain technological solution, a distributed platform targeting the storage, service, and verification of academic and employment qualifications. At this point, attention has to be drawn to the fact that although originally inspired from the field of public education and the need to transform certificates' archiving and management, as well as to fight fraud around education awards, the QualiChain concept has practically a much larger scope, as its services transcend the mere validation of training certificates and bring forward solutions to major challenges of both public and private interest, such as those of lifelong learning, recruitment, mobility, better linking of education with the labor market, etc. thereby accommodating the needs of several stakeholders. The project consortium will pilot QualiChain's innovative combination of technologies in a set of four representative settings, to showcase the impact of the proposed solution on the full spectrum of potential stakeholders (education providers, public administrations selection procedures, HR-consulting for private companies, citizens as learners or employment seekers). In the following section, the pilot case that will have the QualiChain solution applied in the Electrical \& Computer Engineering School (ECE) of the National Technical University of Athens (NTUA) will be described. 


\subsection{University Process Optimization Pilot Concept}

In the light of addressing the challenges described in Section 2, this use case will apply the QualiChain technical solution in the ECE School of the NTUA. The first goal of the pilot will be to take advantage of the platform's blockchain for degree verification as well as for endorsing skills, awards, etc. that students receive during their attendance at the School via smart badges. Using smart badges as a means of enriching students' education profile is a novel idea that was introduced during the initial phases of the project in order to enrich the scope of this specific pilot case. On the other hand, NTUA, being the oldest academic institution for technical education in Greece, is committed to constantly being at the forefront of engineering developments and offering high-quality education services to its students. Moreover, the ECE School of the NTUA has many thematic fields that students can choose from, ranging from software development and computer sciences to energy efficiency and management. As such, this pilot use case will allow the consortium to test the QualiChain Consulting \& Decision Support functionalities in an institution that a) has many different potential career possibilities for alumni that will allow targeting quite a big part of the job market and b) includes technology-related courses from different fields. Consequently, this pilot will leverage QualiChain data analytics and DSS functionalities in order to analyze the labor market requirements around the profession of the Electrical and Computer Engineer, as well as chart the School's current training curriculum and identify gaps and insufficiently addressed knowledge fields, thus providing guidance and decision support for the latter's amelioration in line with the labor market's requirements.

\subsection{Stakeholders Involved}

This particular pilot case revolves around three different groups of stakeholders of the NTUA; students, teachers and the ECE School as a whole. It should be mentioned that the ECE School, as a stakeholder includes various administrative and decision-making bodies such as the school's secretariat, committee, etc.

For this pilot, students of the ECE School were divided into two groups; undergraduate students and Ph.D. students. For undergraduate students, their main needs are finding and selecting the courses that present the most interest for them as well as improving their skills and knowledge so that they will be better prepared to enter the job market after completing their education. As of now, students cannot find specific courses, the curriculum of which also includes the teaching of general skills required in the labor market because the school's curriculum is not organized in such a way. Additionally, they do not have a personal profile where they can track their knowledge curve so they can make more informed decisions for their future. Finally, Ph.D. students have no way of getting recognized for any services they provide to the school such as teaching courses, grading exams, etc. and as such, their role and experiences gained working at the school cannot be validated. The involvement of $\mathrm{PhD}$ students in this specific pilot aims to showcase that they should also be considered as workers of a university whether that is as faculty, researchers or administrative personnel and as such their working experience in academia should be reflected in their professional profiles.

Concerning the added value that professors will receive from QualiChain, this revolves around the update of their courses to include the latest updates in the corresponding technological field and some general skills required by professions that are closely tied with their specific course. At the moment, professors rely exclusively on personal work and their perception to identify advancements/updates in the scientific domain addressed by a specific course. In special cases, they can consult domain professionals and/or employer representatives to identify relevant market requirements but the whole process is manual and time-consuming.

Finally, the main need of the ECE School is the optimization of its administrative processes and its role can be viewed as an amalgamation of the actions that professors and students of the school will be called to participate in. The end-goal for the school (represented by its committee), as it pertains to this pilot, is to modify the current curriculum in a way that will positively impact the skillset and career path of future graduates, improve its score in university rankings and enhance its prestige. At the moment, formal modifications of the curriculum have to follow very strict procedures and usually take place during meetings of the school's committee. 


\subsection{Innovations Applied}

This pilot will take advantage of the platform's blockchain ledger for verification of skills and micro-accreditations (via smart badges) that students receive from participating in seminars, hackathons, special lectures, etc. that are organized under the scope of the school's activities. Additionally, the platform's blockchain will be used to recognize and validate the role of lecturers, Ph.D. students and other stakeholders of the school (apart from students and professors) for the services they may offer to the ECE School. The processes described in this sub-section were a late addition to this pilot in order to expand its scope and take full advantage of the projected platform's functionalities for improving university processes and enriching student profiles. The specifics of these processes can be seen in Figure 1 and will be explained below.

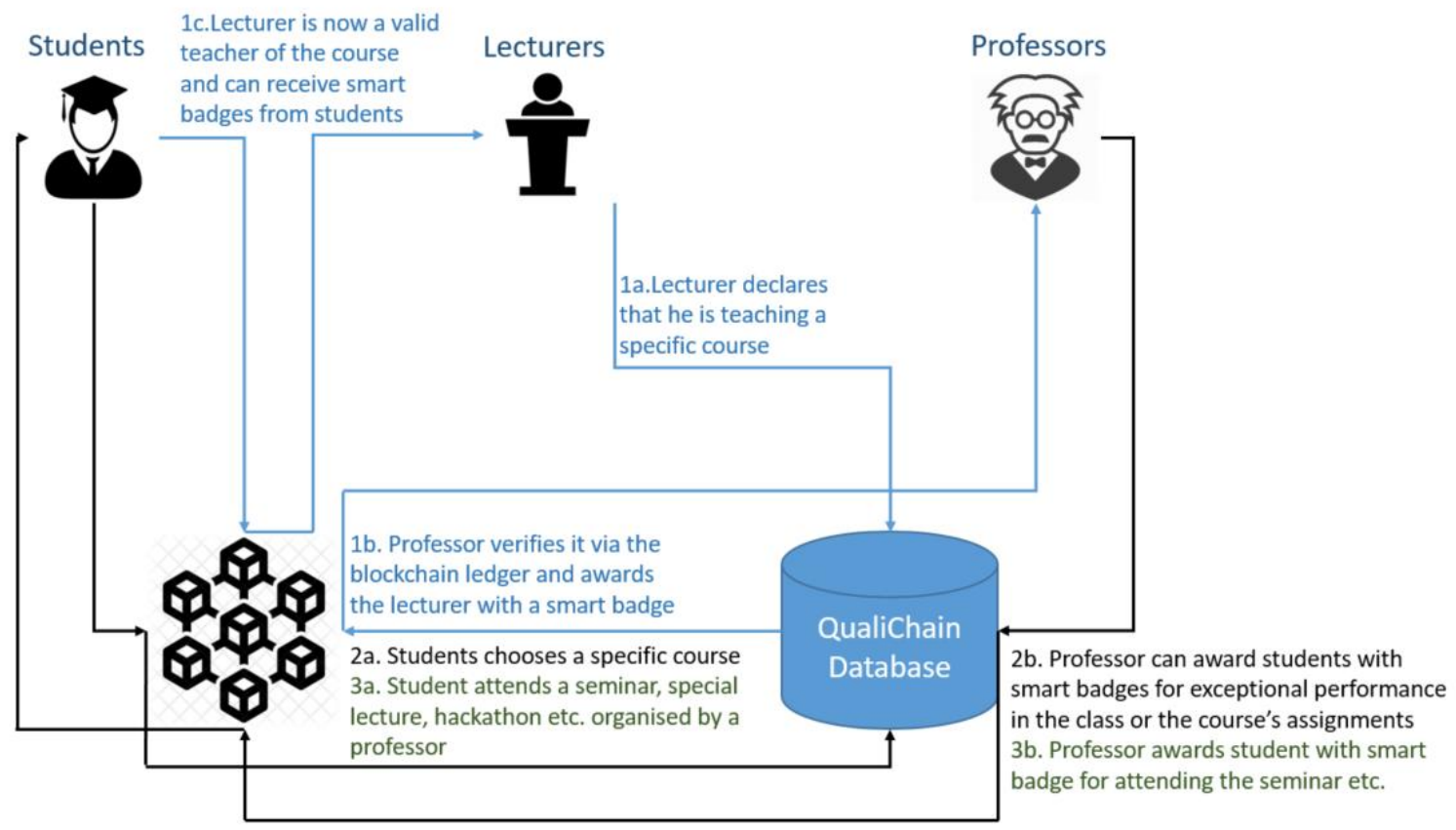

Figure 1. Smart badge endorsement

It can be observed from Figure 1 that smart badges will be mainly awarded from professors to undergraduate students. Given that some courses have group/personal assignments, professors of a course will be able to award smart badges to the students or groups of students that achieved the best results. Such results can include but are not limited to the most efficient algorithms in software-related courses, the best results in group assignments, etc. Moreover, students will be awarded smart badges for attending workshops, hackathons, seminars, special lectures and other activities that are not in the school's curriculum but are organized by the school and fall under the general scope of its activities. Such badges will usually be awarded and verified by the professor(s) that organize such activities and events.

On another note, many courses are being taught not only by the professors but also by lecturers (usually Ph.D. candidates) who are not being recognized their involvement with the course. QualiChain, through this pilot, proposes the following solution: the professor will first verify with a smart badge the lecturer's involvement in the course. During the course, students will be able to award lecturers with smart badges for being communicative, their way of teaching, etc. thus the lecturers of such academic institutions can also get recognized for their efforts and contributions and improve their profile in QualiChain as well. 


\subsection{Use Case Description}

Having explained the role of smart badges in the context of this pilot, the next step was to design the overall process flow between this pilot's stakeholders. The outcome of this task is reflected in Figure 2 that shows the process that will be followed by the pilot's stakeholders. In addition, the figure and the accompanying methodology shows the interaction of the stakeholders with the platform's projected modules and as such will be used as input by the project's technical team to design the input and output flow of data from the platform, as well as design and develop the various modules and services. The main interactions take place between students, lecturers, professors, and the QualiChain platform and the final results stemming from these interactions will be used by the committee of the ECE School to update the curriculum.

The first step of the process will require students to create their profile on the platform. As such, they will use an Intelligent Profiling module that draws data from the platform's database (verified credentials, smart badges) and the web (labor market data, technological developments, etc.), creates the account and saves it in QualiChain. This step is integral to the rest of the procedure given that student data need to be stored in QualiChain in a structured way to be used as input for some of the analyses.

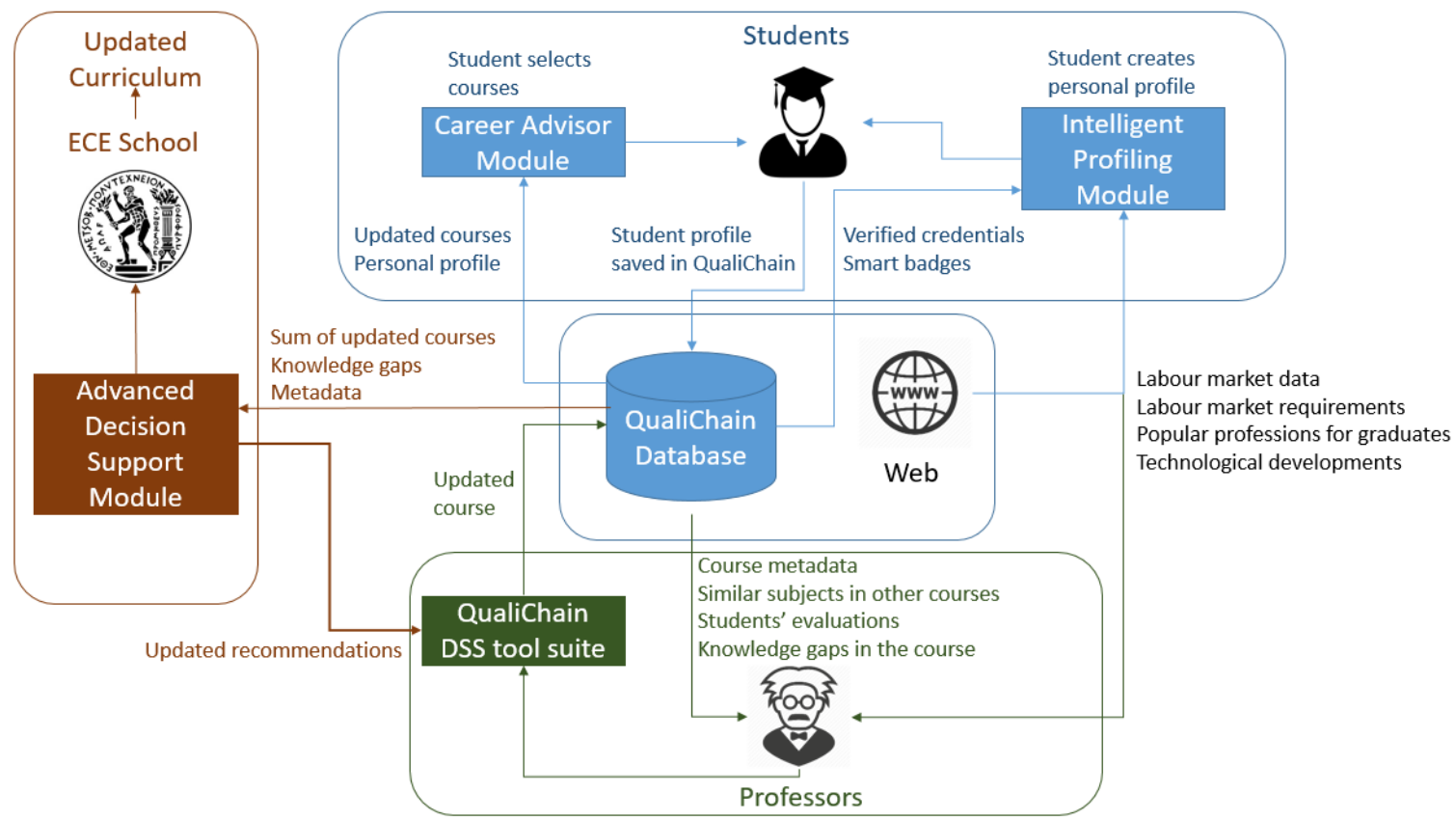

Figure 2. Process flow between stakeholders

The next step of the process requires professors to use the platform's Decision Support System (DSS) tool suite to update their course(s). As such, they will have to insert into the platform information about their course (course metadata). Moreover, past student evaluations that are usually collected with the end of the semester will be semantically enhanced and provided structure so they can be analyzed and assessed along with the rest of the course's data. For using such information as input in QualiChain, university data will be semantically enhanced in order to make the process of data entering by professors as automated as possible.

It should be mentioned that the QualiChain data analytics and DSS tool suite will draw data from QualiChain (student profiles, smart badges, course metadata, student's evaluations, similar subjects, etc.) and the web (labor market data, technological developments, etc.) and has the potential to produce various analyses. Such analyses can either be used by professors for course updates/modifications or by students for decision support on course selection.

When a professor uses the aforementioned services to update a course, the updated course is saved in QualiChain and the updated course description is then synchronized with the Advanced Decision Support Module that will provide updated suggestions for the other courses. Additionally, in case some of the knowledge gaps of the curriculum were addressed in this course, then the system will stop recommending the 
same changes for other courses. Students can then use the Career Advisor module that analyses the student's profile along with the updated course(s) descriptions to provide suggestions on course selection. Finally, the sum of updated courses, knowledge gaps, similar subjects taught in different courses is fed into the Advanced Decision Support module which in turn produces recommendations for a new curriculum for the entire school.

\subsection{BlockChain Potential for University Processes Optimization}

The use case presented in the previous sections, promises to have a positive impact on the ECE School and its students, professors and other personnel. On the one hand, students will possess a holistic personal profile where they can track their learning curve, set goals, receive personalized recommendations and validate their skills and certifications via smart badges. Moreover, the updated curriculum will include a more interesting pool of courses that can provide them with the necessary all-around skill set that is required from the labor market.

Professors of the school will be given a tool that will help them optimize the process of updating their courses. Besides, they will be able to recognize and validate the participation of lecturers and Ph.D. students in courses and other activities through Smart Badges Accreditation. Furthermore, the school's secretariat will avoid time-consuming processes for degree verification and other administrative issues, given that the pertinent documents will exist in QualiChain, secure and already verified. In the long term, all of the aforementioned can lead to an improved reputation for the school as a whole and less time for the employment of graduates.

In the pilot case presented here it is evident that blockchain is mainly useful for the purpose of smart-badge accreditation via a trustworthy and immutable infrastructure. However, that is the case because this pilot focuses on the school's internal processes. Using Blockchain for degree and skill verification can also strengthen the bond between universities (e.g. student transfers) as well as between academia and the labor market and create an ecosystem where pertinent stakeholders can perform everyday tasks more effectively. On the other hand, it can be stated that public and private organisations use their own information systems and will not be able to interact with QualiChain. However, QualiChain is a research project that recognizes the role that blockchain will play in shaping educational and administrative procedures in the future and as such the final solution is projected to be blockchain-agnostic so that it will be able to interact with as many other systems as possible. As such, the role of Blockchain, while being an integral part of this pilot as well, can be better assessed under the scope of QualiChain's projected offerings as a whole.

\section{CONCLUSION}

In this era of rapid digitization, the education sector is still searching for the appropriate level and appropriate methods of digitization. Consequently, student accreditations and documents are mostly used in paper form and their digital equivalents are not flexible enough to be integrated into labor market processes while university IT systems are in most cases inefficient and outdated. QualiChain, the project presented in this paper, recognizes these issues and plans to address them by developing an innovative platform that combines blockchain, semantics, data analytics and decision support algorithmic techniques among others. Furthermore, the pilot that will be applied in the ECE School of the NTUA aims to showcase the benefits of QualiChain in a real-life university environment as well as gather feedback that will be used to improve the platform.

At its current stage, the project has completed the initial research tasks and requirement elicitation stages. Future steps of the project include the elicitation of technical requirements, data gathering for the pilot cases and initiation of the platform development. Specifically, for the pilot presented in this paper, future work will assess the school's current curriculum to identify gaps between labor market needs and the skills developed in the current courses. Furthermore, the specification of the technical assets, such as the ontology that will be used to semantically enhance the school's data and the profiling model that will include all the information related to the user are already underway. Under that context, additional steps include selecting the appropriate data mining techniques and multi-criteria decision support algorithms that will be used on the platform's modules as well as the types of visualizations that will be provided to the users to facilitate a complete overview of the data that they investigate. 


\section{ACKNOWLEDGEMENT}

This work has been co-funded by the European Union's Horizon 2020 research and innovation programme under the QualiChain project, Grant Agreement No 822404.

\section{REFERENCES}

Association of Universities in the Netherlands (VSNU) (2017): Digitisation in academic education. Our agenda for a future-proof range of degree programmes. Available online at https://www.vsnu.nl/files/documenten/VSNU\%20Digitisation\%20in\%20academic\%20education.pdf.

Chapman, David W.; Lindner, Samira (2014): Degrees of integrity. The threat of corruption in higher education. In Studies in Higher Education 41 (2), pp. 247-268. DOI: 10.1080/03075079.2014.927854 .

Daniel, Ben (2015): Big Data and analytics in higher education. Opportunities and challenges. In Br J Educ Technol 46 (5), pp. 904-920. DOI: 10.1111/bjet.12230 .

Gräther, Wolfgang et al. (2018): Blockchain for Education. Lifelong Learning Passport.

Hazelkorn, E. (2007): The impact of league tables and ranking systems on higher education decision making. In Higher Education Management and Policy 19 (2), pp. 1-24. DOI: 10.1787/17269822 .

Koedinger, $\mathrm{K}$ et al. (2008): An open repository and analysis tools for fine-grained, longitudinal learner data. In 1st International Conference on Educational Data Mining, Montreal, pp. 157-166.

Mohamedbhai, Goolam (2016): The Scourge of Fraud and Corruption in Higher Education. In IHE (84), p. 12. DOI: 10.6017/ihe.2016.84.9111 .

Rooksby, John; Kristiyan, DImitrov (2017): Trustless education? A blockchain system for university grades. In New Value Transactions: Understanding and Designing for Distributed Autonomous Organisations, Workshop at DIS.

Sharples, Mike; Domingue, John (2016): The Blockchain and Kudos. A Distributed System for Educational Record, Reputation and Reward. In Katrien Verbert, Mike Sharples, Tomaž Klobučar (Eds.): Adaptive and adaptable learning. 11th European Conference on Technology Enhanced Learning, EC-TEL 2016, Lyon, France, September 13-16, 2016, Proceedings / Katrien Verbert, Mike Sharples, Tomaž Klobučar (eds.), vol. 9891. Switzerland: Springer (LNCS sublibrary. SL 3, Information systems and applications, incl. Internet/Web, and HCI, 9891), pp. 490-496.

Skiba, Diane J. (2017): The Potential of Blockchain in Education and Health Care. In Nursing education perspectives 38 (4), pp. 220-221. DOI: 10.1097/01.NEP.0000000000000190 .

Sony Global Education (2016): Sony Global Education Develops Technology Using Blockchain for Open Sharing of Academic Proficiency and Progress Records. Available online at http://www.sony.net/SonyInfo/News/Press/201602/16-0222E/index.html.

South African Council on Higher Education (2013): The Aims of Higher Education. Pretoria - South Africa: Council on Higher Education (9). Available online at https://www.che.ac.za/sites/default/files/publications/kagisano9.pdf.

Turkanovic, Muhamed et al. (2018): EduCTX. A Blockchain-Based Higher Education Credit Platform. In IEEE Access 6, pp. 5112-5127. DOI: 10.1109/ACCESS.2018.2789929 .

University of Nicosia (2017): Academic Certificates on the Blockchain. Available online at http://digitalcurrency.unic.ac.cy/free-introductory-mooc/academic-certificates-on-the-blockchain/. 